\title{
Gossip as a Burdened Virtue
}

\author{
Mark Alfano $^{1} \cdot$ Brian Robinson $^{2}$
}

Accepted: 13 April 2017 / Published online: 1 May 2017

(C) The Author(s) 2017. This article is an open access publication

\begin{abstract}
Gossip is often serious business, not idle chitchat. Gossip allows those oppressed to privately name their oppressors as a warning to others. Of course, gossip can be in error. The speaker may be lying or merely have lacked sufficient evidence. Bias can also make those who hear the gossip more or less likely to believe the gossip. By examining the social functions of gossip and considering the differences in power dynamics in which gossip can occur, we contend that gossip may be not only permissible but virtuous, both as the only reasonable recourse available and as a means of resistance against oppression.
\end{abstract}

Keywords Virtue $\cdot$ Burdened virtue $\cdot$ Gossip $\cdot$ Reputation $\cdot$ Social epistemology

"The only time people dislike gossip is when you gossip about them."

- Will Rogers

\section{Introduction}

Talking about others behind their back is a time-worn tradition. It can be a fun way to pass the time or a cathartic way to blow off steam, but gossip and related speech acts can also be deeply serious. In 1990, furor over sexual misconduct at Brown University boiled over. The walls of the women's bathroom in the university library became a canvas for rape accusations. The names of as many as thirty male students eventually made it onto the list, which, despite being scrubbed clean by janitorial staff multiple times, was often updated. The New York Times quoted one of those named as saying, "I've been labeled guilty with no chance to defend myself" (Celis 1990). A similar list, with

Mark Alfano

mark.alfano@gmail.com

Brian Robinson

prof.brobinson@gmail.com

1 Delft University of Technology, Delft, Netherlands

2 Texas A\&M-Kingsville, Kingsville, TX, USA 
four names, was written on the walls of multiple women's bathrooms in and around Columbia University in 2014. ${ }^{1}$ In 2015, a petition at change.org called on Ohio University to ban the ACACIA fraternity for engaging in systematic sexual assault and rape. The petition cited and screencapped posts on Yik Yak, the anonymous geo-located social media app, as evidence against the fraternity. A specific "blue house" located at 591/2 N Court Street was identified as ground zero for the fraternity's systematic sexual assaults, and Google still returns multiple pictures of the stigmatized house. ${ }^{2}$

We are not in a position to assess these particular episodes, but we think they make the stakes clear: talking about people behind their backs can have serious consequences. In this paper, we explore the morality of such speech acts. Though the class of speech acts in which we're interested is not perfectly captured by the folk notion of gossip, the overlap is substantial, so we will refer to our target as 'gossip'. We argue that a disposition to gossiping well can be what Lisa Tessman (2005) calls a "burdened virtue." As we explain in more detail in section 5, Tessman contends that in the context of oppression, certain traits become virtues for people in systematically disempowered situations, which can be used in the pursuit of flourishing in the context of oppression and as means of helping others who are similarly disadvantaged.

To argue that gossip is a burdened virtue, we must first consider gossip's nature and function, tasks we take up in sections 2 and 3. Gossip is a normatively laden speech act that functions as a means of partner control and partner choice through ostracism. By gossiping, we warn others about wrongdoers (including oppressors) and call for a collectively safer means of punishing wrongdoers than direct confrontation. The primary objection against gossip is that it can be - and often is - false. In section 4, we add complexity to the functional analysis by thinking through the fact that — while much gossip is false or misleading - much of it is true. This means that we can only evaluate gossip by attending to both moral and epistemic considerations. We consider examples of gossip by the oppressed about their oppressors throughout, through which the benefits of gossip for the oppressed become apparent. In section 5, we conclude that since it is in gossip by the oppressed about their oppressors that gossip most clearly fulfills its useful moral functions, gossip is a burdened virtue. It should be noted that unlike many virtues such as humility, honesty, or wisdom, the trait of gossiping well lacks a common name. Hence, for lack of a better term, we will extend our use of 'gossip' from the speech act to refer to speak of gossip as a burdened virtue.

\section{A Triadic Relational Framework for Gossip}

To begin it is necessary to refine our understanding of what gossip is, since it is notoriously difficult to define by specifying necessary and sufficient conditions. Nevertheless, several aspects of gossip are fairly uncontroversial and will suffice for our purposes. First, as Lind et al. (2007) note, gossip occurs within a triadic relationship of speaker, hearer, and subject. Intuitively, one cannot gossip about oneself or the person(s) to whom one is speaking. In the paradigmatic case, you gossip to one person about some absent third party. ${ }^{3}$ Any analysis of

\footnotetext{
${ }^{1}$ Retrieved February 11, 2016 http://www.theguardian.com/education/2014/jun/26/columbia-universitystudents-rape-list-mishandle-sexual-assault.

${ }^{2}$ Retrieved February 12, 2016 from https://www.change.org/p/community-members-against-sexual-violenceban-acacia-chapter-at-ohio-university.

${ }^{3}$ Adkins (2002) argues that stipulating the third party be absent implies cowardice on the part of the speaker. As we discuss in section 5 , there are many occasions where speaking behind someone's back seems not only prudent, but even virtuous.
} 
gossip must consider all three relata in this triad. Alfano (2016a) suggests that, while Gray et al. (2012) are right to parse morality in terms of the agent-patient dyad, the richness of human morality can only be understood if such dyads are allowed to iterate: $\mathrm{X}$ acting on (Y acting on Z). Gossip is a prime case of such richness.

It also matters who gossips about whom to whom. It also matters what the gossip is about, i.e., the topic of the gossip. Not just any comment fitting this pattern counts as gossip. In a word, gossip is supposed to be juicy. Without precisely defining how a statement about an absent third party is juicy, we can note two facets that are germane to our present purposes. First, it can't be common knowledge. If I tell you that Barack Obama was the 44th President of the United States, it strains credulity to say that this counts as gossip. Second, the topic of gossip typically seems to involve some sort of norm violation, either by the subject or the speaker. Robinson (2016) distinguishes between evaluative and idle gossip. Evaluative gossip assesses the absent subject by some normative criterion; for example, "Vanessa is lazy," "Ewan stole \$20," or, "Sam has the ugliest haircut." In these examples, the speaker negatively evaluates the subject for an alleged norm violation. The kind of norm in question can be of just about any sort: moral, legal, cultural, aesthetic. Idle gossip, on the other hand, is about some topic that is generally frowned upon; for instance, discussing the subject's income or sex life can be gossip, even if no judgment or condemnation is expressed. The speaker is violating a norm by broaching the frowned upon topic (and likely intends the audience to recognize this fact).

In this paper, we focus on evaluative gossip. Most evaluative gossip offers a negative evaluation of the absent subject, such as "Pam is a liar." Pam has allegedly violated the moral norm of truth-telling, and the speaker condemns her for it. Gossip understood broadly as talking evaluatively about someone who is not present, can also be positive (Holland 1996), such as saying "Penny is a paragon of honesty."

Some additional points about gossip are worth mentioning. First, gossip can be either true or false. What makes a speech act gossip are the social context and the intentions of the speaker, not the truth-value of the propositions she asserts. (The speaker's intentions are typically based around the moral psychological function of gossip, which we address in the next section.) Second, though rumors and gossip share much in common, gossip need not be unsubstantiated hearsay. The speaker can even know the content of the gossip firsthand, as evidenced by the lists of rapists at university campuses noted above. Third, though feminist epistemologists are right to note that gossip often occurs within the larger context of a narrative (Code 1995; Adkins 2002), gossip can also occur independently of a narrative context (again as the rapists lists indicate). Fourth, it is important to note the role of gender in defining this concept. Gossip has typically been regarded both by the folk and by feminist philosophers as a speech act predominately engaged in by women (de Sousa 1994, Jones 1980, Spacks 1982, Tannen 1990, and Collins 1994). We, however, follow Adkins (2002) in noting that gossip is not distinct to women's speech, though it does raise topics relevant to feminist philosophy.

Fifth, the speaker can gossip about someone as a moral agent by characterizing his behavior ("Ford lied") or his traits ("Ford is a liar"); the speaker can also gossip about someone as a moral patient by characterizing the treatment he's received (e.g., "Ford is a cuckold," as in Shakespeare's Merry Wives of Windsor). Besides evaluating their targets, attributions of traits do at least two things: they describe why the subject acts as he does, and they suggest that he will behave similarly in the future. Trait-based gossip is arguably the most predictively useful form, and hence will be our primary focus. Behavior-based gossip only discusses one or a few of the subject's past behavior(s), and patiency gossip discusses not what the subject has done 
but what has been done to him. As Robinson (2016) emphasizes, forewarned is forearmed: trait-based gossip has significant potential to impact the subject. If the gossip is negative, it can lead to his ostracism as a means of protecting others from him. If the gossip is positive, it recommends the subject to others as someone who can be trusted to conform to the norm in question. Furthermore, if the gossip is false, it creates a caricature of the subject as a villain or hero. Such caricatures may have value in the context of moral education, but one naturally worries that, even in the case of flattering caricatures, the speaker erects unfair or overly demanding expectations for the subject.

Finally, when gossiping, power relationships matter. Much of the existing literature on gossip examines gossip between social equals, either exclusively among women (Coates 1989; Jones 1980) or among generic agents (Westacott 2011; Bertolotti and Magnani 2014). In reality, this often is not the case. Oppressed individuals may have little recourse but to gossip among one another about their oppressors. Differences in power dynamics can radically alter the moral permissibility of gossip. We expand on these points below.

\section{The Moral Psychological Functions of Gossip}

For Aristotle, to understand what it is to be an $X$ must often be answered in terms of the function of $X$. To be a flutist or sculptor (for instance), one must play the flute or sculpt well enough. In order to see why gossiping well might count as a virtue, it is first imperative to consider the moral psychological functions of gossip. A speaker can then be said to be gossiping well or not based on how well her gossip fulfills these functions. The primatologist Robin Dunbar $(1996,2004)$ has gone so far as to argue that the evolutionary origin of language is the fact that it facilitates gossip and thereby enhances the human capacity for cooperation. We needn't go that far, but we agree that gossip is best understood in relation to cooperation and protection.

Evaluative gossip is a response to norm violation. We often feel compelled to report a norm violator to other people. But why? People have a menu of options for handling different sorts of norm violations and violators, ranging from rewarding good behavior to punishing bad behavior, but also including both abandonment and ostracism. Martin and Cushman (2015) persuasively argue that direct punishment is best understood as a kind of partner control, whereas ostracism is best understood as a form of partner choice. ${ }^{4}$ Robinson (2016) characterizes the moral psychological functions of gossip in terms of ostracism of a norm violator. We propose extending and combining these two views to more fully capture the moral psychological functions of gossip. Specifically, we contend that gossip has three primary moral psychological functions: guiding partner choice, implementing partner control, and directing the hearer to adhere to certain norms while committing the speaker to the same norms. Since gossip involves a triad of agents, both hearer and subject can be partners of the speaker, though the function of gossip for each is intermingled with the other. So, we will briefly explicate the nature of partner control and partner choice in general and then explain how they function for both hearer and subject. The background for this contention is the idea

\footnotetext{
${ }^{4}$ A third potential function of gossip is to help the speaker to form an adequate self-conception by expressing in language her own experiences and values (Collins 1994). This is especially valuable for people who suffer from what Fricker (2007) calls hermeneutical injustice, which occurs when people in subordinate power relations lack adequate conceptual and linguistic resources to make sense of and verbalize their own experiences.
} 
that communication about morality helps people to reap the benefits of cooperation while avoiding the pitfalls of free riding and betrayal.

\subsection{Partner Control and Partner Choice}

In cases of partner control, $\mathrm{X}$ uses incentives or disincentives to ensure that $\mathrm{Y}$ cooperates with $\mathrm{X}$ in a way that is sufficiently advantageous to $\mathrm{X}$. These incentives and disincentives can be backward-looking (i.e., rewards and punishments) or forward-looking (promises of reward and threats). Yet, because partner control is paradigmatically direct, it is liable to backfire. Why should I cooperate with you right after you punished or threatened to punish me? Why should I trust you when you manipulate me by altering my incentives? Partner control can be enhanced, though, by third-party reward and punishment, in which $\mathrm{Z}$ becomes aware of Y's treatment of $\mathrm{X}$ and responds to $\mathrm{Y}$ 's cooperation and free-riding by helping or harming Y, respectively. ${ }^{5}$ Partner control that relies on third parties in addition to the partner herself is more robust than partner control that is only enforced by the partner herself because it outsources monitoring and incentivizing. But even such enhanced partner control is liable to backfire if $\mathrm{Y}$ sees $\mathrm{Z}$ as just a minion or catspaw of X.

Partner choice is more indirect. In this framework, $\mathrm{X}$ does not intervene in her ongoing potentially-cooperative relationship with $\mathrm{Y}$ to ensure that $\mathrm{Y}$ lives up to his end of the bargain, nor does $\mathrm{X}$ rely on $\mathrm{Z}$ to do so. Instead, $\mathrm{X}$ uses whatever information she has ready-to-hand to choose between $\mathrm{Y}$ and other potential partners. How can X make such a choice rationally? She needs to know whether or to what extent $\mathrm{Y}$ is competent and good-willed (at least towards her). For this reason, partner choice is typically backward-looking. $\mathrm{X}$ will tend to avoid or ostracize partners who previously defected, and will tend to renew cooperative engagements with partners who previously proved trustworthy. Past behavior is treated as inductive evidence of a stable underlying trait that is liable to manifest in further behavior in the future. Such evidence is of course defeasible, but one may have nothing else to go on when selecting a partner. In addition, such evidence may be comparative rather than absolute, while still being practically useful. If $\mathrm{X}$ is deciding whether to cooperate with $\mathrm{Y}$ or $\mathrm{Z}$, what matters most is which of them is more likely to prove trustworthy, not the absolute probability of defection for each of them.

As in the case of partner control, partner choice can be enhanced by third parties. In particular, X needn't base her assessment of Y's prospects as a cooperative partner using only Y's track-record with $\mathrm{X}$ herself. We learn from experience, but not just our own experiences; the more clever and prudent among us also learn from the experiences of others. Given this, if third parties who more or less share X's values are willing to disclose their accurate-enough assessments of $\mathrm{Y}$ as a potential partner for $\mathrm{X}$, they will provide extremely useful information. For this reason, gossip - if it is accurate and relates to the stable, cross-situationally consistent dispositions of the subject - is an invaluable resource in partner choice. And once more, the value of such information may be comparative rather than absolute. If $\mathrm{X}$ is faced with partnering with either Y or Z, neither of whom she knows from Adam, then a third party's

\footnotetext{
${ }^{5}$ Nowak and Sigmund (2005) have argued that such "indirect reciprocity" accounts for the prevalence of altruistic, cooperative interactions, and dispositions in the human population. They define indirect reciprocity primarily in positive terms: I help you and somebody else helps me. But it can also be characterized in negative terms: I harm you and somebody else harms me (i.e., third-party punishment).
} 
saying that $\mathrm{Y}$ is untrustworthy while $\mathrm{Z}$ is trustworthy may be sufficient reason for $\mathrm{X}$ to opt for $\mathrm{Z}$.

\subsection{Subject, Hearer, and Speaker}

Suppose $\mathrm{Y}$ has wronged $\mathrm{X}$ by not cooperating. $\mathrm{X}$ then gossips about $\mathrm{Y}$ 's wrongdoing to $\mathrm{Z}$. By gossiping, the speaker aims to influence the hearer's own partner choice (against Y). X's intent is to warn $\mathrm{Z}$ that, from a prudential or moral point of view, $\mathrm{Y}$ should be ostracized. In fact, warning others is often one of the most salient features of gossip, as is apparent in the lists of alleged rapists in women's restrooms that we mentioned above. Such gossip is meant altruistically to benefit the hearer either by helping them to avoid being wronged by $\mathrm{Y}$ (if the gossip is negative) or by encouraging them to interact with $\mathrm{Y}$ (if the gossip is positive).

With regard to the subject, gossip can serve both as a means of partner control and as means of partner choice. Continuing with the same example, in gossiping, $X$ 's intent is to prompt $Z$ to ostracize $Y$ as form of punishing $Y$. This precisely conforms to the pattern of third-party partner control. Z's ostracism of Y is meant to teach Y a moral lesson. De Pinninck et al. (2008) developed a computer model of gossiping. Their simulations found that as the percentage of gossip about norm-violators increased, so too did the utility of cooperating, while the utility of non-cooperation fell off exponentially. Note furthermore that, just because X gossips about Y, $\mathrm{X}$ herself needn't ostracize $\mathrm{Y}$ as well. Due to pre-existing power dynamics between $\mathrm{X}$ and $\mathrm{Y}$, direct ostracism of $\mathrm{Y}$ by $\mathrm{X}$ may be too costly for $\mathrm{X}$, and for this reason she may outsource the ostracism to $\mathrm{Z}$ in order to engage in partner control of $\mathrm{Y}$. For instance, $\mathrm{X}$ may be highly reluctant to ostracize her vindictive boss, and so gossip about them instead to encourage others not working for them to punish or ostracize them. Additionally, $\mathrm{X}$ may expect $\mathrm{Z}$ to repeat the gossip, propagating it through Y's social network. Although second-hand and third-hand gossip may not be as evidentially valuable as first-hand gossip, its function as a signal boost (making the cost of norm enforcement lower for all involved and protecting all involved from bad actors) is very important. In computer science, it's been shown that, depending on the topology of a communicative network, almost everyone gets the message even when the probability of any particular agent gossiping is between 0.6 and 0.8 (Haas et al. 2006). This reduces redundant information flows and, in the real world, may protect gossipers from the people about whom they gossip.

Perhaps the more intuitive case involves the gossiper ostracizing the wrongdoer herself, in addition to encouraging the hearer to join in that ostracism. This isn't partner choice itself, but is an announcement of the gossiper's choice to ostracize Y. Note that, in this case too, gossip can still function as a means of partner control. The ostracism of Y need not be (and typically shouldn't be) inexorable. In that case, $\mathrm{X}$ intends for the group ostracism of $\mathrm{Y}$ to incentivize $\mathrm{Y}$ to change or make amends in order for the ostracism to be lifted.

With regard to the hearer, as we already noted, gossip puts the hearer on notice that she would do best to avoid the subject (or in the case of positive gossip, that she would do well to partner with the subject). Whether the hearer heeds this advice often does not directly affect the wellbeing of the speaker, and therefore cannot be considered a form of partner control. But gossip may serve another function. By gossiping, the speaker may signal her or his expectations of the hearer and the consequences of fulfilling or violating those expectations. Envision a case in which $\mathrm{X}$ is gossiping to $\mathrm{Z}$ about $\mathrm{Y}$, who violated a norm. In many cases, $\mathrm{Z}$ can take $\mathrm{X}$ also to be implying a threat of punishment or ostracism should $Z$ behave as $Y$ did. This threat disincentivizes such norm violations for $\mathrm{Z}$, and hence gossip can function as a means for 
partner control of the hearer as well as the subject. More generally, then, gossip signals that the speaker is prepared to reward or punish people, including the hearer, based on the norms referenced in the gossip, and thus directs the hearer to adhere to those norms as well.

Additionally, gossip typically commits the speaker to the norms referenced in the gossip. This is precisely why it is almost self-contradictory to gossip about someone for being a gossip. Likewise, if $\mathrm{X}$ gossips about $\mathrm{Y}$ for being a liar, but $\mathrm{X}$ subsequently lies to the hearer of her gossip, $\mathrm{X}$ turns out to be both a liar and a hypocrite. Naturally, not all gossip fulfills all of the functions sketched out in this section. For instance, slut-shaming is a kind of gossip. Armstrong et al. (2014) have shown that high-status women engage in slut-shaming gossip with each other about lower-status women without taking themselves to be subject to the same sexual norms. In such cases, the ostracism of the subject is present without the commitment of the speaker or directing of the hearer. Alternatively, one can gossip about the dead or celebrities whom one will never meet. Here the ostracism is absent, though the speaker may still express that the norm in question still applies to the speaker or hearer. Interestingly, Savarimuthu et al. 2013 demonstrate the effectiveness of gossip's commitment and direction by showing that gossip is a practical means for groups with differing norms to self-sort, so that (for instance) cooperators partner with other cooperators and free-riders with other free-riders.

The moral psychological functions can then be summarized as initiating ostracism to cooperatively punish (alleged) norm violators and protect others, while also committing the speaker to the norm in question. Naturally, not every instance of gossip will fulfill all of the functions described here, though paradigmatic examples of gossip will display many of them. Just as a pianist must play the piano often enough and well enough to actually be a pianist, one with the virtue of gossiping well gossips often enough (but not too much) and typically fulfills these functions. One easy way to not gossip well is erroneous gossip.

\section{Erroneous Gossip}

For gossip to be effective, it must be trustworthy. Drawing on both ethnographic data and agent-based simulation, Giardini and Conte (2012) have argued that gossip reduces the costs (to speaker, hearer, and subject) of social control when compared with direct punishment, and that - under conditions of sufficiently frequent and truthful communication - gossip preserves the benefits associated with systems of punishment. This way of construing the informational value of gossip suggests that gossip will tend to be more valuable if it comes from a trusted source, even more so if the trusted source is known to share one's own values. Furthermore, gossip will tend to be more valuable if it is directly about or serves as a basis for inferences about the subject's moral (and perhaps intellectual) character. Knowing that a prospective partner once violated a norm is less valuable than knowing that they are disposed to such norm-violations in the future.

Finally, gossip will tend to be more valuable when it is about people who are strangers to the hearer. If I gossip to you about your sibling or your partner, you may update your assessment of their character somewhat, but it's likely that you already have a robust impression of them, which is resilient to my chitchat. As Nehamas (Nehamas 2010, p. 238; see also Alfano 2016b) points out, "friendship is immune, or at least resistant, to slander: we know our friends well and it takes much to undermine our faith in their goodness." By contrast, if I gossip to you about a near or complete stranger, I may have to overcome your faith in humanity (in the case of negative gossip) or your cynicism (in the case of positive 
gossip), but my words are not likely to have to fight the sort of uphill battle required to alter your conception of your friend (or your enemy). Except in cases of outright fabrication, gossip will propagate in the first instance from people who have directly experienced or observed the subject of gossip. But gossip is notoriously repeatable, engendering the sorts of chains and webs of transmission explored by Coady (1992) and others who work on the epistemology of testimony and social epistemology. Our knowledge about many prospective cooperative partners relies on second-hand (or even third-, fourth-, or fifth-hand) information.

In a society where both positive and negative gossip are at least somewhat likely to transmit others' somewhat accurate impressions of you, protecting your reputation will tend to be a worthwhile undertaking (Hayes et al. 2017). Provided that people are aware of the possibility of gossip and of their own need for cooperative partners, they will realize that they have an incentive not to prove untrustworthy (which could result in negative gossip and subsequently a shrunken pool of potential partners) and to prove trustworthy (which could result in positive gossip and subsequently an enlarged pool of potential partners). This reputational concern could be purely instrumental. Online darknet markets such as Silk Road and Alphabay seem to function well enough through reputation scores, despite the facts that transaction-partners cannot identify one another in real life (Wehinger 2011) and that they presumably do not have a lot of faith in one another's humanity. ${ }^{6}$ In such contexts, users only demonstrate an instrumental concern for their reputation, as it affects their ability to buy and sell illicit goods. But it stands to reason that intrinsic concern for reputation would function even better than instrumental concern, as it would be more robust, since they one would protect his reputation regardless of whether or not his reputation provided any instrumental benefit.

If this is right, then a community in which people engage in accurate-enough gossip enough of the time, know that they do so, and care about their reputations instrumentally or (even more so) intrinsically is one in which people will tend to regulate their own behavior in such a way that their reputations are protected or even enhanced. In such a community, gossiping well helps to stabilize the system, whereas gossiping poorly perverts, subverts, or even destroys it.

Because gossip can be true or false, it is necessary to evaluate how well gossip can fulfill its moral psychological function cooperative punishment of (alleged) norm violators and protection of others under different conditions of verisimilitude. This means that we can only evaluate gossip by attending to both moral and epistemic considerations, which we take to be impossible to disentangle (following Fricker 2007). Building on the framework proposed by Alfano and Skorburg (Forthcoming), we distinguish three stages at which error can degrade the convention of gossip: errors at the source, errors in transmission, and errors in reception.

\subsection{Errors at the Source}

If you make an erroneous character trait judgment, then any subsequent report of that judgment will be inaccurate. ${ }^{7}$ For the last two decades, philosophers have worked on digesting evidence from personality and social psychology related to this point. Those influenced by the situationist tradition in social psychology have offered a variety of pessimistic interpretations

\footnotetext{
${ }^{6}$ Darknet networks cannot be found through traditional search engines (e.g., Google) or accesses with standard communication protocols. They are often used for nefarious purposes (drug-trafficking or cyber-crimes) or enhanced privacy.

${ }^{7}$ It might end up functioning as a self-fulfilling prophecy in Alfano's (2013) sense, who argues that the language of character is often used not just to describe, predict, explain, or evaluate behavior, but also to control behavior. But such false gossip will not be an accurate report of an independently pre-existing trait.
} 
of this evidence, ranging from the possibility that almost no one possesses any virtues or vices (Harman 2000) to the worry that the virtues and vices people do possess are extremely narrow in their field of application (Doris 2002) to the skeptical position that, regardless of whether people have virtues and vices as they are traditionally understood, we are almost never in a position to know whether someone has a particular trait (Alfano 2011).

We will avoid taking a controversial stance here, working from a few points of consensus that seem to have emerged in the literature. First, it's hard to know whether someone has a particular trait unless you're very well acquainted with her or him. This is related to the more general metaphysical observation that it is difficult to know of any object whether it has a disposition unless you've observed and perhaps even interacted with it in a variety of conditions. Character traits are dispositions of human agents, so it's hard to know about them too (Alfano 2014). Second, people have an unfortunate tendency to jump to conclusions about other people's dispositions based on scant evidence. This problem was first explored under the rubric of the fundamental attribution error (Ross 1977, p. 183): the notion that people are prone to attribute most or all observed behavior by others to internal, dispositional factors rather than external, situational ones. More recently, psychological researchers such as James Uleman and his colleagues (Uleman et al. 1996, p. 211) have explored spontaneous trait inferences, which occur "when attending to another person's behavior produces a trait inference in the absence of our explicit intention to infer traits or form an impression of that person." Research in this area suggests that people spontaneously and automatically draw global inferences about the dispositional traits of others based on their actions or their appearance, even when situational constraints are conspicuously present (Fiske and Taylor 1991; Willis and Todorov 2006; Uleman et al. 2008).

None of this research demonstrates that character traits do not exist, but it does point to a worry about the epistemology of character. We are liable to make mistakes about people, especially those we do not know well. But as we saw above, gossip is most useful when it is about subjects who are (near) strangers to the hearer. Putting these points together, it now looks like gossip has the best combination of epistemic and practical value when the speaker is well acquainted with the subject (or has responsibly received reliable testimony about the subject) but the hearer is not.

\subsection{Errors in Transmission}

Fricker (2007) argues that the virtue of testimonial justice is a disposition to lend appropriate credence to the assertions of others. Naïve testimonial justice might be possible for those uncorrupted by their upbringing and culture, but most people need to develop corrective testimonial justice, tamping down their credence in those who don't deserve it and bumping up their credence in those who do. As Alfano and Skorburg (Forthcoming) argue, the virtues of naïve and corrective testimonial justice are only part of the story. They are the virtues of a good receiver of testimony, but there are also the congruent virtues of a good transmitter of testimony. H. Paul Grice famously articulated the Cooperative Principle: "Make your contribution such as it is required, at the stage at which it occurs, by the accepted purpose or direction of the talk exchange in which you are engaged" $(1989$, p. 26) and the four conversational maxims that clarify it:

(Quality) Try to make your contribution one that is true.

(Quantity) Make your contribution as informative as is required. 
(Relevance) Be relevant.

(Manner) Be Perspicuous.

Setting aside quibbles about Gricean exegesis, these maxims seem like pretty good rules for a virtuous speaker to follow.

One can easily imagine cases in which the maxim of Quantity requires a speaker to provide to the audience certain information about an absent third party, but doing so would be gossip. The speaker, not wanting to be a gossip, then violates the maxim of Quantity and engages in self-censorship. For instance, consider the case of Jeremy and Super-Hans from the British television comedy Peep Show. Jeremy has found employment as a personal assistant to an eccentric and highly inappropriate millionaire. He quickly learns that he is expected to perform sex acts with his employer. One day, Jeremy arranges for his friend Super-Hans to fill in for him, but fails to tell Super-Hans about the employer's sexual expectations. Afterward, SuperHans confronts Jeremy (Armstrong et al. 2007):

SUPER-HANS: Why didn't you tell me about the wanking-off bit?

JEREMY: Sorry, I didn't think -

SUPER-HANS: Yeah, well, you should have bloody thought. Jesus!

One cannot help sympathizing with Super-Hans. The maxims of Quantity and Relevance, partialistic moral obligations to Super-Hans, and basic decency jointly required Jeremy to have gossiped. Beyond thoughtlessness, one main reason for such self-censorship is the social norm against gossiping and the related fear that one would be branded a gossip. It is therefore a relief to point out that Peters and Kashima (2014) have found that, despite the widespread notion that gossip is always morally wrong, gossiping is often perceived as a moral act, and that gossipers who share highly diagnostic morality information are perceived as especially moral individuals. They interpret these results in functionalist terms: the most important things to know about a stranger are whether they are trustworthy/moral and whether they are competent. Information that illuminates these two basic dimensions has high utility, so providing it to another person is seen as a kind of benevolence.

Thus, the convention of gossip can fall apart if people gossip too little. Perhaps the more intuitive concern is that it can fall apart if people gossip too much. Cass Sunstein (2014) helpfully diagnoses such surfeits of gossip in terms of informational cascades and reputational cascades. An informational cascade occurs when a claim propagates through a community without people bothering sufficiently to assess its accuracy before repeating it. When this happens, the community's level of credence in the claim increases because everyone has heard it and everyone knows that everyone has heard it. In the absence of explicit contradictions of the claim, a perception of consensus emerges. A reputational cascade occurs when people refrain from correcting - and sometimes even endorse - gossip that they know to be false in order to curry favor or avert blame. According to this characterization of the spread of false gossip, then, the fault lies in a violation of the maxim of Quality. Speakers who repeat gossip that they do not know to be true or which they even know to be false propagate misinformation. In addition, speakers who fail to contradict gossip they know or suspect is false may undermine the conventions that make gossip functional. As we argued above, one function of gossip is protect the hearer of gossip from untrustworthy partners, but this function can only be fulfilled to the extent that the hearer trusts the speaker. There may be cases in which false gossip could be asserted or left un-contradicted in order to protect the hearer (perhaps she wouldn't believe a damning truth, but would believe a compelling falsehood). In such cases, locally fulfilling one function of gossip (protecting this hearer from that untrustworthy 
potential partner) comes into tension with respecting the conditions for the possibility of gossip itself (hearers' ability to trust gossiping speakers). We are not in a position to say how this tension should be resolved in all cases. ${ }^{8}$

\subsection{Errors in Reception}

Finally, there are errors in reception, where the informational value of a statement is degraded due to the audience's confusion about what was communicated or the reliability of what was communicated. Errors in reception can arise for mundane reasons. For instance, I might fail to comprehend your gossip because you speak softly and I am hard of hearing. Or I might fail to take on board your gossip because I view you as an inveterate liar and trouble-maker, so I put no faith in your utterances. More germane to gossip, though, are errors about the credibility of the speaker's meaning. Such errors have already been explored under the heading of testimonial injustice by Fricker (2007). According to Fricker, testimonial injustice occurs when the hearer systematically accords either too much or too little credence to the speaker's words, and does so because of epistemically irrelevant features of the speaker. Giving the speaker too much credence is a credibility excess. Fricker spends very little time diagnosing the problems associated with credibility excesses because she thinks the more serious epistemic injustice involves a credibility deficit: giving too little credence to the speaker's words. If I don't believe what you say in part because you are a woman, I manifest such a credibility deficit. And if I do so systematically to all or many women, I embody a species of the vice of epistemic injustice. In a similar vein, Sunstein (2014) argues that preconceptions and stereotypes make certain items of gossip seem credible. He is therefore most interested in cases of credibility excess that result from epistemically irrelevant features of the subject, not the speaker.

Gossip, as a kind of assertion, can be received with epistemic injustice, of which there are several varieties. First, there is credibility excess that results from epistemically irrelevant features either of the speaker (e.g., I believe white men, especially police officers) or of the subject of the gossip (e.g., I believe what you tell me about a black woman because she's a black woman). Credibility deficits follow the same pattern, wherein the audience does not believe the speaker because of epistemically irrelevant features either of the speaker (e.g., I disbelieve your rape accusation because you're a woman) or of the subject (e.g., I disbelieve your rape accusation because it's about a member of the college football team). In a recent example, Daniel Holtzclaw was convicted of raping multiple poor black women, most of whom initially declined to come forward. One testified in a pre-trial hearing, "I didn't think that no one would believe me." 9 Ample evidence shows that women making rape accusations often have to overcome pervasive skepticism (Brown et al. 2007). Finally, there can be special cases where features of speaker and subject interact to enhance or reduce credibility deficits and excesses (e.g., I would normally disbelieve a rape accusation by a black woman, but since it's made against a black man, I accept it).

\section{The Virtue of Gossiping Well}

As Westacott (2011) notes, the trait of being a gossip is typically regarded as a vice. While he presents reasons it might turn out to be a virtue, he considers the matter inconclusive. We

\footnotetext{
${ }^{8}$ Thanks to Nancy Snow for raising this point.

${ }^{9}$ Retrieved February 6, 2016 from http:/www.theguardian.com/us-news/2015/dec/11/daniel-holtzclaw-formeroklahoma-city-police-officer-guilty-rape.
} 
contend that consideration of power dynamics that are often at play in gossip reveals the disposition to gossip in certain ways and for certain reasons is a burdened virtue. To make this claim, we will first consider what it would mean for gossiping well to be a virtue. We then will argue that gossip by the oppressed about their oppressors satisfies the criteria for a virtue (and perhaps uniquely so). Hence, a fine-tuned disposition to gossip is a burdened virtue.

There is much to be said in favor of gossip. As we already saw, it is often motivated by altruistic intent to help others, while also disincentivizing norm violation. Furthermore, gossiping is a way of performatively endorsing or contravening a system of norms and values. When the oppressed gossip about their oppressors, it is a low-cost and relatively safe mechanism for fighting against the norms and values of their oppressors. Since gossip can be an effective tool of protection and resistance for the oppressed, it is no wonder that gossip has traditionally been regarded (by those in power) as a vice and more frequently attributed to women. By claiming that gossip can be virtuous, we aim to vindicate this means of resistance.

Gossiping well is a subtle, reasons-responsive mean between the vices of excessive gossip and deficient gossip. Thus, we are construing gossip in Aristotelian terms. Gossip can be excessive in a variety of ways, such as quantity: for instance, repeating gossip that the hearer already knows, or contributing to a reputational cascade. It can be excessive when the speaker gossips to too many hearers, thereby failing to take into account how they're liable to interpret the gossip or what benefit it might have for them. Gossip can also be excessive when it is about too many people or the wrong people. For instance, gossip based on the fundamental attribution error or the thoughtless acceptance of someone else's unreliable gossip is excessive in this sense. Gossip can also be excessive when it over-represents what the speaker is in a position to know or suspect with sufficient credibility. Likewise, gossip about someone the hearer knows quite well is typically excessive, and gossip about people who are unlikely to commit the same offense again is excessive. Perhaps even more clearly, gossip about people in their capacity as moral patients (e.g., victim blaming) is almost always excessive. Finally, gossip is excessive when it is motivated by too many and the wrong reasons (e.g., malice, pettiness, a desire to scapegoat or inspire mobbing). ${ }^{10}$

Gossip can also be deficient in several ways, beginning with quantity. The case of SuperHans illustrates this well: Jeremy was negligent for not gossiping. Think of the errors in transmission discussed above. It can be deficient when it under-represents what the speaker is in a position to know as merely a rumor. It can be insufficient when the speaker gossips to too few hearers, thereby failing to protect innocents. Likewise, gossip can be deficient when it is not done about serious offenders, especially serious offenders who enjoy a position of power or prestige that tends to insulate them from direct punishment and challenge. Finally, gossip is deficient when it is motivated by too few of the right reasons (e.g., desire to protect the hearer). Also in this vein, gossip is inappropriate when it performatively endorses immoral norms, such as gossip "outs" and condemns someone who is currently in the closet.

As should now be clear, navigating between these vices of excess and deficiency in relation to gossip requires a subtle social intelligence, awareness of multiple competing norms, and a good will. One might summarize this by saying that gossiping well requires phronesis. If this is right, then gossiping well is a virtue, but, because gossip typically has such value for especially for the oppressed as a means of resisting their oppressors, it in many cases it will qualify as a burdened virtue. Tessman (2005, pg. 95) describes burdened virtues as "traits that make a contribution to human flourishing [...] only because they enable survival of or resistance to

$\overline{10}$ Thanks to an anonymous referee for emphasizing this point to us. 
oppression." If, for instance, student victims of rape and sexual assault could reasonably expect that universities offered sufficient institutional protection of victims and prosecution of rapists, then they could rely on such institutions and avoid gossiping. However, institutional betrayal, rather than support, often seems to be the norm (Smith and Freyd 2014). Many news stories (such as the recent reports about Baylor University, e.g., Gottlieb 2016) recount universities failing to properly investigate rape allegations, harassing rape victims, or failing to punish student rapists. Such institutional stonewalling prompts those marginalized, victimized, and ignored by those charged with protecting them to turn to gossip as a means of protecting the wellbeing of others.

Gossip by the oppressed about their oppressors is often neither excessive nor deficient. The systematic oppression they face is a serious enough transgression to merit reaction, and gossip offers a relatively safe means for cooperatively ostracizing oppressors. It is not motivated out of pettiness, but out of a desire to protect others that are similar subject to oppression. While gossip about a whole group as oppressors may be excessive, gossip warning against individual oppressors rarely is. Likewise such gossip does not typically over-represent what the speaker is in a position to know or suspect with sufficient credibility. Because such gossip is neither excessive nor deficient, it falls with the Aristotelian mean as virtue. Since such gossip contributes to the flourishing of the oppressed because of their oppression, gossip is a burdened virtue.

There remains a final deep-seated concern against the moral permissibility of gossip in general and the lists of rapists specifically. In general, one should be afforded the opportunity to restore one's reputation when it is damaged. Reputation repair can be accomplished either by making restitution (such as making amends or apologizing) or by demonstrating that the accusations were false. Since we know that sometimes gossip is false, allowing for those gossiped about to show that it is false is critical. Otherwise, gossip is liable to be overly punitive in at least two ways: it could punish those who aren't even guilty, and it could punish too severely those who are guilty but not diabolical villains. Corresponding to these two kinds of over-punitiveness, there are two opportunities the subjects of gossip should ordinarily be afforded. First, they should have an opportunity to correct false accusations. (As we mentioned above, The New York Times quoted one of the Brown University students accused of rape saying, "I've been labeled guilty with no chance to defend myself.") Second, even if the gossip was true, they should be allowed the opportunity to abate the reputational damage, at least after some time. You may have lied to me twenty years ago, but I probably shouldn't still be gossiping about it now.

The problem, however, is that gossip is typically done in private, so that the subject will not know he or she is being gossiped about. That ignorance prevents the subject from repairing his or her reputation; the subject doesn't know it is in need of repair in the first place. This is the fundamental moral tension in which gossip exists. In some cases, the moral demand of allowing for reputation repair outweighs the good gossip can do. To gossip privately about how you once stole $\$ 5$ is certainly insufficient to outweigh your right to reputation repair. Being accused of rape (especially without knowing it or being able to defend against it) is a weighty harm to the subject. When the gossip is true, the reputational harm is generally deserved. Some names on the Brown and Columbia lists may have been false gossip, however, and these individuals couldn't effectively defend themselves. This potential harm of being wrongfully accused must be weighed against the benefit to the audience in the context of the alternatives available to the speaker. The most obvious benefit to the audiences of these lists is increased protection from being raped, the significance of which cannot be downplayed. When 
a speaker has another reasonable alternative to gossip (i.e., one that allows the subject to respond to the accusations), then that option may be preferable. For instance, if a speaker is a peer of the subject, then the gossip is often not permissible because it is private. The subject should be allowed to respond. Even worse, if the speaker is in a position of power over the subject, gossip becomes a tool of oppression by secretively damaging her or his reputation. Yet, when the speaker is at a significant power disadvantage, such that it would be difficult or costly to make a public accusation, gossip may be not only permissible but virtuous, both as the only reasonable recourse available and as a means of resistance against oppression.

Open Access This article is distributed under the terms of the Creative Commons Attribution 4.0 International License (http:/creativecommons.org/licenses/by/4.0/), which permits unrestricted use, distribution, and reproduction in any medium, provided you give appropriate credit to the original author(s) and the source, provide a link to the Creative Commons license, and indicate if changes were made.

\section{References}

Adkins KC (2002) The real dirt: gossip and feminist epistemology. Social Epistemology 16(3):215-232

Alfano M (2011) Explaining away intuitions about traits: why virtue ethics seems plausible (even if it isn't). Review of Philosophy and Psychology 2(1):121-136

Alfano, M. (2013). Character as moral fiction. Cambridge University Press

Alfano M (2014) What are the bearers of virtues? In: Sarkissian H, Wright JC (eds) Advances in Experimental moral psychology. Continuum, New York, pp 73-90

Alfano M (2016a) Moral psychology: an introduction. Polity, London

Alfano M (2016b) Friendship and the structure of trust. In: Webber J, Masala A (eds) From Personality to Virtue: Essays in the Psychology and Ethics of Character. 186-206. Oxford University Press

Alfano, M. \& Skorburg, A. (Forthcoming). Extended knowledge, the recognition heuristic, and epistemic injustice. In D. Pritchard, J. Kallestrup, O. Palermos, \& A. Carter (eds.), Extended Knowledge Oxford University Press

Armstrong, J. (Writer), Bain, S. (Writer), \& Martin, B. (Director). (2007). Handyman [Television series episode]. In J. Armstrong (Producer), Peep Show. London: Channel 4

Armstrong, E. A., Hamilton, L. T., Armstrong, E. M., \& Seeley, J. L. (2014). “Good girls”: gender, social class, and slut discourse on campus. Social Psychology Quarterly

Bertolotti T, Magnani L (2014) An epistemological analysis of gossip and gossip-based knowledge. Synthese 191(17):4037-4067

Brown JM, Hamilton C, O'Neill D (2007) Characteristics associated with rape attrition and the role played by scepticism or legal rationality by investigators and prosecutors. Psychology, Crime \& Law 13(4):355-370

Celis, W. (1990). Date rape and a list at Brown. New York times. Retrieved February 12, 2016, from http://www. nytimes.com/1990/11/18/us/date-rape-and-a-list-at-brown.html

Coady, C. (1992). Testimony: a philosophical study. Oxford University Press

Coates J (1989) Gossip revisited: language in all-female groups. In: Coates J, Cameron D (eds) Women in their speech communities. Routledge, London, pp 94-122

Code L (1995) Rhetorical spaces: essays on gendered locations. Routledge, New York

Collins L (1994) Gossip: A feminist defense. In: Goodman R, Ben Ze'ev A (eds) Good gossip. University of Kansas Press

De Pinninck AP, Sierra C, Schorlemmer M (2008) Distributed norm enforcement via ostracism. In: Coordination, organizations, institutions, and norms in agent systems III. Berlin Heidelberg, Springer, pp 301-315

De Sousa R (1994) In praise of gossip: indiscretion as a saintly virtue. In: Goodman R, Ben Ze'ev A (eds) Good gossip. University of Kansas Press

Doris J (2002) Lack of character: personality and moral behavior. Cambridge University Press

Dunbar R (1996) Grooming, gossip and the evolution of language. Faber and Faber, London

Dunbar R (2004) Gossip in evolutionary perspective. Review of General Psychology 8(2):100-110

Fiske S, Taylor S (1991) Social Cognition. McGraw-Hill, New York

Fricker M (2007) Epistemic injustice: power and ethics in knowledge. Oxford University Press, Oxford

Giardini F, Conte R (2012) Gossip for social control in natural and artificial societies. Simulation: Transactions of the Society for Modeling and Simulation International 88(1):18-32 
Gottlieb, J. (2016, October 28). Report: Baylor regents say 19 football players accused of sexual assault since 2011. The Washington Post. <URL = https://www.washingtonpost.com/news/early-lead/wp/2016/10/28 /report-baylor-regents-say-19-football-players-accused-of-sexual-assault-since-2011/>. Retrieved 17 November 2016

Gray K, Waytz A, Young L (2012) The moral dyad: a fundamental template unifying moral judgment. Psychological Inquiry 23(2):206-215

Grice P (1989) Studies in the way of words. Harvard University Press, Cambridge, Massachusetts

Haas Z, Halpern J, Li L (2006) Gossip-based ad hoc routing. IEEE/ACM Transactions on Networking (TON) 14(3):479-491

Harman G (2000) The nonexistence of character traits. Proceedings of the Aristotelian Society 100:223-226

Hayes TL, Hogan R, Emler N (2017) The psychology of character, reputation, and gossip. In: Fileva I (ed) Questions of character. Oxford University Press

Holland MG (1996) What's wrong with telling the truth? An analysis of gossip. American Philosophical Quarterly 33(2):197-209

Jones D (1980) Gossip: notes on women's oral culture. Women's Studies International Quarterly 3(2-3):193-198

Lind PG, da Silva LR, Andrade JS Jr, Herrmann HJ (2007) Spreading gossip in social networks. Physical Review E 76:036117

Martin J, Cushman F (2015) To punish or to leave: distinct cognitive processes underlie partner control and partner choice behaviors. PloS One 10(4)

Nehamas A (2010) Aristotelian philia, modern friendship? In: Inwood B (ed) Oxford Studies in ancient philosophy, pp. 213-47. Oxford University Press

Nowak M, Sigmund K (2005) Evolution of indirect reciprocity. Nature 437:1291-1298

Peters K, Kashima Y (2014) Gossiping as a moral social action: a functionalist account of gossiper perceptions. In: Forgas J, Vincze O, Laszlo J (eds) Social cognition and communication. Psychology Press, New York, pp 185-202

Robinson B (2016) Character, caricature, and gossip. The Monist 99(2). doi:10.1093/monist/onv036

Ross L (1977) The intuitive psychologist and his shortcomings. In: Berkowitz (ed.) Advances in Experimental psychology, vol. x. Academic Press, New York, pp 174-214

Savarimuthu S, Purvis M, Purvis M, Savarimuthu BTR (2013) Gossip-based self-Organising agent societies and the impact of false gossip. Minds and Machines 23:419-441

Smith C, Freyd J (2014) Institutional betrayal. The American Psychologist 69(6):575-587

Spacks P (1982) In praise of gossip. The Hudson Review 35(1):19-38

Sunstein C (2014) On rumors: how falsehoods spread, why we believe them, and what can be done. Princeton University Press

Tannen D (1990) You just Don't understand: women and men in conversation. Ballantine Books, New York

Tessman L (2005) Burdened virtues: virtue ethics for Liberatory struggles. Oxford University Press

Uleman J, Newman L, Moskowitz G (1996) People as flexible interpreters: evidence and issues from spontaneous trait inference. In: Zanna (ed.) Advances in Experimental social psychology, vol. xxvii. Academic Press, San Diego, pp 211-280

Uleman J, Saribay S, Gonzalez C (2008) Spontaneous inferences, implicit impressions, and implicit theories. Annual Review of Psychology 59:329-360

Wehinger F (2011) The dark net: self-regulation dynamics of illegal online markets for identities and related services. Intelligence and security informatics conference (EISIC), European, 209-13. Institute of Electrical and Electronics Engineers

Westacott E (2011) The virtue of our vices. Princeton University Press, Princeton

Willis J, Todorov A (2006) First impressions: making up your mind after 100ms exposure to a face. Psychological Science 17:592-598 